\title{
Arquivo da língua. Língua do arquivo: Procura-se Lenora de Barros, Paulo Bruscky, Ricardo Aleixo
}

Resumo: $\mathrm{O}$ artigo busca analisar sob a ótica do arquivo, alguns procedimentos artísticos nas obras de Lenora de Barros, Paulo Bruscky e de Ricardo Aleixo, estabelecendo uma reflexão sobre a língua na poesia e nas artes plásticas.

Palavras-chave: Poesia, Arquivo, Língua, Procedimento, Artes Visuais

Abstract: The article seeks to analyze, from an archival perspective, some of the artistic procedures in the artworks of Lenora de Barros, Paulo Bruscky, and Ricardo Aleixo, establishing a reflection on language in poetry and in the visual arts.

Keywords: Poetry, Archive, Language, Artistic Procedures, Visual Arts

\section{Arquivo: Experimentum linguae}

Em termos de estética e política, mas também em seleção e combinação, a língua dispõe de condições materiais para ser discutida na relação entre arquivo e poesia. Os poetas dispõem da palavra não apenas em termos de material verbal, mas reinventam um uso plástico por meio de arranjos sintáticos, pelo ritmo, pela inteligência gráfica e sonora e até mesmo pela agramaticalidade. Tanto no sentido mais amplo quanto no mais específico, a língua pode ser considerada um grande arquivo do qual poesia seleciona e combina os signos dela postos em uso. Ademais, os poetas lembram que as palavras não são regidas apenas pelas normas gramaticais, mas passam a ocupar o espaço a partir de 
uma errância em termos rítmicos, visuais e até mesmo táteis. Em Essais de Linguistique Générale, Roman Jakobson observa que a "agramaticalidade efetiva priva um enunciado de sua informação semântica” (2003 [1963]: 206).

Os procedimentos poético-artísticos, mesmo uma agramaticalidade possui uma temperatura informacional capaz de ressemantizar o que não foi semantizado. Por exemplo, artistas como Paulo Bruscky (Recife, 1949) e Lenora de Barros (São Paulo, 1953) exploram a dimensão táctil da língua, gerando obras que poderiam ser chamadas de arquivo agramatical da língua, sobretudo em obras em que a própria língua, na sua dimensão anatômica, possui uma presença material. Já Ricardo Aleixo (Belo Horizonte, 1960), por um lado, a dissemina foneticamente através de arranjos vocais, cujas partículas assemânticas se tornam significantes que também podem ser ressemantizados pela própria crítica e, por outro, ele faz com que as palavras escorram na superfície do papel.

Existe na prática arquivista da língua tanto uma reeducação dos sentidos quanto uma pedagogia, nem sempre institucional, que se abrem a práticas de leitura: os poetas nos ensinam a ler o mundo desde os níveis mais elementares da linguagem. A partir de artistas que põem a poesia nos limites de uma "textura gramatical" (Jakobson 1973: 229) poderia se buscar no arquivo da língua, uma língua do arquivo cujas assimetrias entre som e sentido podem gerar dissidências imperceptíveis em termos de micropoéticas, para afirmá-lo com Marjorie Perloff (2021a) que adota marcos teóricos que vão de Victor Shklovsky a Haroldo de Campos, cujo ponto de contato é o próprio Roman Jakobson, citado por ela: "qualquer coincidência fonológica é sentida como um parentesco semântico" (2021a: 13). Ao que se poderia acrescentar a uma ideia de experimentum linguae que a partir do próprio arquivo surge a seguinte variante: qualquer não-coincidência fonológica é sentida como uma aliança semântica, fato que é perceptível ao longo da tarefa da crítica das vanguardas, na qual a própria obra de Perloff pode ser incluída.

As vanguardas históricas - mas não só elas - abriram formas mais estruturadas e expuseram microestruturas da língua, a saber, a força expressiva das sílabas, o deslocamento das letras - onde coincidem e não coincidem -, evocando, sobretudo, a dimensão física e vocal da língua, independentemente do idioma ao qual as peças foram veiculadas ou vocalizadas. Tais fatos ajudam uma consciência para a inteligência da frase, para a força imanente de um único verso ou de uma palavra, seja através de sua repetição ou do esgotamento do sentido, como se pode ler na obra de Paulo Bruscky, "Poema de repetição", de $1978 .{ }^{1}$ De tanto repetir o sintagma "Poema de repetição" ao longo de 2'55", praticamente no mesmo ritmo, as palavras começam a falhar: a repetição às vezes se torna "recepção". O ritmo monocórdico também leva a frase ao esgotamento do próprio sentido, cujo termo sempre se volta para si. O próprio sintagma "poema de repetição" é ressemantizado pelo gesto de repetição: a respiração do artista passa a ser um significante, assim como todo o ato de fala que doravante encontra na obra um espaço para o arquivo da voz do artista. 
Em Chercher une phrase, Pierre Alferi escreveu que existe um balanço de estruturas rítmicas com uma velocidade que ocupa outro sistema circulatório, de modo que versos e frases possuem sintaxes que não são - apenas - de natureza gramatical (2007: 24-25). Esse modo de ultrapassar a gramática pode ser considerado uma política da relação entre arquivo e poesia, muito embora, seja preciso afirmar que a gramática nunca é totalmente ultrapassada pois se ela não persiste em termos de textura, como propôs Jakobson, ela produz um limiar comum, em termos semiológicos e semióticos permitindo sempre que códigos sejam compartilhados a partir de um interesse (inter-esse) comum, compreendido literalmente como um "estar entre".

A língua do arquivo possui uma gramática e um gosto: suas normas classificatórias dispostas ao uso comum pode ter um sabor único para aqueles que o sentem a ponto de dispô-la novamente em circulação, dado que, virtualmente, um arquivo pode retornar a qualquer momento. Arlette Farge, em $\mathrm{O}$ sabor do arquivo, ajuda a recompor tanto a difícil materialidade de um mundo desaparecido quanto a sua virtualidade em termos de língua, dado que o "sabor", cujo título original é mais literal, gosto ("goût") pode muito bem ser atravessado pelo sentido da gustação que pode ir da língua, ao sentir e repetir as palavras à inteligência da mão ao manipular vestígios íntimos, assombros de fragmentos que fazem parte de gestos que originariamente não existiram para serem fixados, classificados e ordenados. Segundo Farge: "O arquivo petrifica esses momentos ao acaso e na desordem; aquele que o lê, que o toca ou que o descobre é sempre despertado primeiramente por um efeito de certeza. A palavra dita, o objeto encontrado, o vestígio deixado tornam-se representações do real" (2009 [1989]: 18). Em termos de uma língua do arquivo, entende-se que tanto artistas da palavra quanto poetas alimentam o acaso e a desordem do arquivo da língua reduzindo-os às suas obras e, com isso, sentem o gosto das palavras que retornam ao mundo em termos de objetos únicos, as próprias obras. Em relação ao caráter da consciência do uso das palavras, há artistas que possuem afinidades com as práticas que os poetas têm em relação ao novo uso dado às palavras. Eles possuem uma consciência da língua que vem de um saber e do uso dos códigos linguísticos, pois a estrutura rítmica das palavras e sua disposição visual da língua são levadas em consideração no texto literário. ${ }^{2}$

No breve experimentum linguae do arquivo, pode-se acrescentar a perspectiva de Daniel Heller-Roazen que retorna à noção de função poética, de Jakobson, para pôr em questão a sua existência, afirmando ainda que ele "está dissimulada não apenas para o público, mas também para os poetas, e não apenas recentemente, nem ainda desde muito tempo, mas desde sempre. Enfim, com ela, as estruturas poéticas não cessaram de emergir e de persistir, quase incógnitas, simultaneamente familiares e escapando de todos" (2017: 174). Pela descrição de Heller-Roazen, pode-se imaginar a própria função poética do arquivo, familiar e fugitiva, disseminada no fio dos tempos pelos artistas, poetas e por seus leitores, visitantes ou espectadores de sua circulação. 


\section{Do gosto concreto do arquivo}

Um exemplo fortemente presente no Brasil que merece ser lido em termos de língua do arquivo foi o movimento da poesia concreta no final dos anos cinquenta. Haroldo de Campos (1929-2003), Décio Pignatari (1927-2012) e Augusto de Campos (1931) elaboraram um grande repertório de traduções das mais diferentes tradições literárias, dos poetas provençais a Stéphane Mallarmé, de James Joyce a Maiakovsky, por exemplo; recuperaram outros autores no Brasil que tinham caído no esquecimento como foi o caso de Oswald de Andrade (1890 - 1954) e Sousândrade (1833-1902), para ficar apenas em dois exemplos. Em paralelo a isso, eles estabeleceram afinidades visuais entre a palavra, as formas plásticas e as estruturas rítmicas. Por extensão a estas atividades, eles desenvolveram os estudos da semiologia e da semiótica no Brasil, sobretudo Haroldo de Campos e Décio Pignatari.

Em um texto publicado originalmente no dia primeiro de setembro de 1957, "a moeda concreta da fala", Augusto de Campos retoma uma questão que ocupou a linguística, pelo menos na perspectiva jakobsoniana, mas segue sua argumentação por Susanne Langer e, sobretudo, pelo linguista Edward Sapir, referência de Jakobson, e de quem Augusto de Campos se vale para o título do ensaio. Augusto de Campos chama os poetas à responsabilidade da vida diante da linguagem para que esta não persista apenas por inércia e sem coloração vital (2006 [1957]: 160). Esse é o princípio de vida dos arquivos movimentado por poetas e artistas, pois a dimensão vital e dinâmica da língua - não apenas o português brasileiro - se situa nestas idas e vindas da própria língua que, entre arquivo e repertório, faz com que a própria poesia movimente a sua "moeda concreta da fala" (Sapir in Campos, 2006 [1957]: 164).

No caso da poesia concreta, ela representa um vasto arquivo ainda a ser explorado para a crítica literária e artística, para a tradução e para o fazer poético. Aquém e além da poesia concreta como projeto, diversas foram as práticas poéticas nas quais se inventaram novas situações para o espaço da língua no Brasil, estabelecendo performances únicas nas páginas de jornais, como é o caso da artista Lenora de Barros e ainda mesmo sob o registro de meios precários tais como a fotocópia, a colagem e a reprodução gráfica de cartazes para mencionar apenas três procedimentos que se combinam com práticas artísticas de Paulo Bruscky.

A voz, na sua condição significante, também será analisada em um sentido mais amplo do arquivo. Assim, a precariedade dos meios também deve incluir uma disposição do uso da voz, no caso de poetas e de artistas que realizam performances nas quais a voz é um elemento estruturador indispensável, inclusive para o texto escrito. Esse é o caso do poeta e artista Ricardo Aleixo (1960). Aleixo se vale de um amplo e vasto arquivo de tradições afro-brasileiras, da própria memória familiar e de técnicas vocais e do corpo para montar ritmicamente, no tempo de uma performance, fragmentos da opinião pública retiradas de notícias de jornal, relatos de violência, atos falhos, ditados populares, fazendo da relação entre língua e arquivo a sua prática cotidiana de composição. Em 2019, no contexto da exposição Meta-Arquivo: 1964-1985, no Sesc, em São Paulo, ${ }^{3}$ Ricardo Aleixo leu autos de 
qualificação e arquivos de interrogatórios policiais feitos no período da ditadura para a instalação do artista Paulo Nazareth (1977). A passagem da linguagem técnica e escrita do interrogatório ganhou a dimensão oral quando lido em voz alta pelo poeta e que os visitantes podiam ouvir em headphones. A exposição buscou criar espaços de escuta e de leitura de histórias da ditadura cívico-militar brasileira (1964-1985). O arquivo subleva um capital material e simbólico em um espaço de disputa, dado que antigos espaços que pertenciam à esfera da ditadura em São Paulo, por exemplo, o Departamento de Ordem Política e Social - DEOPS-SP, é atualmente parte da Pinacoteca do Estado por onde circulam aproximadamente oitenta e cinco mil visitantes.

Da leitura feita por um poeta de arquivo da ditadura militar brasileira, dois aspectos merecem ser considerados: em um primeiro momento, emergem cenas da vida cotidiana como o percurso de ônibus no final do dia, relatos de desempregados e agrupamentos de pessoas em espaços públicos. Pode-se apresentar uma transformação da ordem das coisas: por um lado, o cotidiano ficou sob suspeita: aqueles que seguiam suas tarefas habituais que corriam risco, pois poderiam desaparecer da noite para o dia e, de outro, as suspeitas se propagaram pelo cotidiano: qualquer poderia ser um policial, militar à paisana ou informante. Toda e qualquer prática subversiva deveria ser acobertada pela vida cotidiana, isto é, esconder-se e diluir-se na rotina, pois esta seguia fortemente vigiada. O ritmo da voz de Ricardo Aleixo não deixa de reproduzir o tom monocórdico de um interrogatório transcrito em uma máquina de datilografar na qual, sob a ótica do Estado, os mínimos exercícios de poder do cidadão comum poderiam ser exercidos através da denúncia de toda e qualquer atividade considerada suspeita. Em um segundo momento, a própria leitura feita por um poeta negro transmite outra tonalidade do relato impessoal vindo de documentos policiais, cuja linguagem praticamente está de acordo com o destino de um boletim de ocorrência: a produção de um arquivo cujo sentido está fechado em si mesmo, ele é controlado até mesmo pela linguagem técnica e protegido de interpretações exteriores à linguagem da lei, dos artigos do código e do direito penal. Se o tom da voz expõe a firmeza e a fragilidade do cotidiano, ao reproduzi-lo mimeticamente ele produz uma diferença política: aqueles que escutam estes depoimentos selecionados do arquivo do DEOPS-SP estão expostos aos rastros históricos dos quais estes arquivos fazem parte.

\section{Arquivo e Guerrilha Gráfica}

Os arquivos deste período sombrio da história do Brasil ainda circulam de modo restrito e não são todos os artistas e pesquisadores que se valem destes arquivos para colocá-los em movimento. Não se trata apenas de resumir esta prática a uma arte estritamente política, no sentido que política muitas vezes é condicionada ao panfletário. O ponto mais preciso desse arquivo está nas circulações dos corpos, das palavras e dos signos que se comunicam através da língua, para entender esse aspecto com o ensaio de Walter Benjamin, "Sobre a linguagem em geral e sobre a linguagem humana”, de 1916. 
Benjamin observou argutamente os detalhes materiais da língua no "através" e sua correlação com a marcação espiritual presente no pronome reflexivo "se" para enfatizar o caráter imediato (Unmittelbarkeit) das palavras. O sentido mais imanente do uso das palavras pelos poetas é conferir-lhes uma prática semeadora de uma guerrilha. No período ditatorial, e isso ocorre com regimes políticos totalitários, as palavras devem estar limpas e com um uso muito bem definido, sem margens de ambivalência. Paulo Bruscky relata que o período de maior violência e repressão ocorreu entre 1969 e 1974. Nesta época, ele fazia intervenções públicas nas ruas de Recife, cidade localizada na região nordeste do Brasil. Por alterarem o uso limpo das palavras no cotidiano, suas obras foram consideradas suspeitas, porque o artista despertava no público uma participação inabitual, embora essa participação não tivesse por finalidade manifestações panfletárias. Mesmo assim o artista foi preso. Na primeira vez em que o artista foi interrogado pela polícia, ele percebeu técnicas especializadas na forma com a qual os policiais elaboravam as perguntas: "eu sei que o conceito de arte é bem aberto", disse um deles, "se eu colocar uma pedaço qualquer do chão no muro, isso é arte?" O artista responde: "se você fizer isso, não; se eu fizer, sim" (2014: 81). A resposta difere do repertório de arquivos da polícia lidos por Ricardo Aleixo que tinha na sua totalidade trabalhadores pobres, negros e desempregados. O testemunho de Paulo Bruscky não deixa de levantar outro aspecto: a que esfera da censura é um modo de delimitar o repertório da língua. Assim, a resposta do artista não deixou de ecoar nas práticas com as quais Paulo Bruscky questiona os limites da originalidade da obra de arte e a distância mínima entre suas práticas e o debate artístico entre formalismo e história tocado pelas microestruturas da língua e da arte que a obra de Bruscky atinge: não apenas são incorporados os elementos semânticos da cópia e do original, em que o artista datilografa em duas folhas separadas "original" e "cópia", mas o procedimento em si de copiar, de alterar, de montar panfletos feitos com carimbos, formulários, cartões postais, selos, recortes de jornal e da disposição dos signos no espaço gráfico e urbano. Ou seja, o artista se vale da linguagem dos panfletos para produzir um outro material, cuja semântica é tão política quanto as palavras de ordem "abaixo a ditadura”. Essa prática de Bruscky será, aliás, fundamental para o arquivo que o artista criou com correspondência, obras de outros artistas, poemas, panfletos, livros de artista e recortes de jornal, totalizando mais setenta mil objetos. Trata-se de um arquivo que pode ser considerado como um acervo de uma guerrilha gráfica-visual.

Literalmente, a passagem dos anos sessenta para os anos setenta no Brasil também foi marcada por movimentos de guerrilha, cujo maior representante foi Carlos Marighella (1911-1969), líder comunista que foi considerado o inimigo número um do regime ditatorial. A guerrilha deu um tom de resposta para a violência e repressão do Estado. Sob esta ótica, voltar-se para estes anos com um olhar à poesia e à arte praticada por Paulo Bruscky expõe uma estética de guerrilha cultural figurado no exemplo da obra, desta vez impressa, "Repetition Poem” (“Poema de Repetição”) (Fig. 1) 


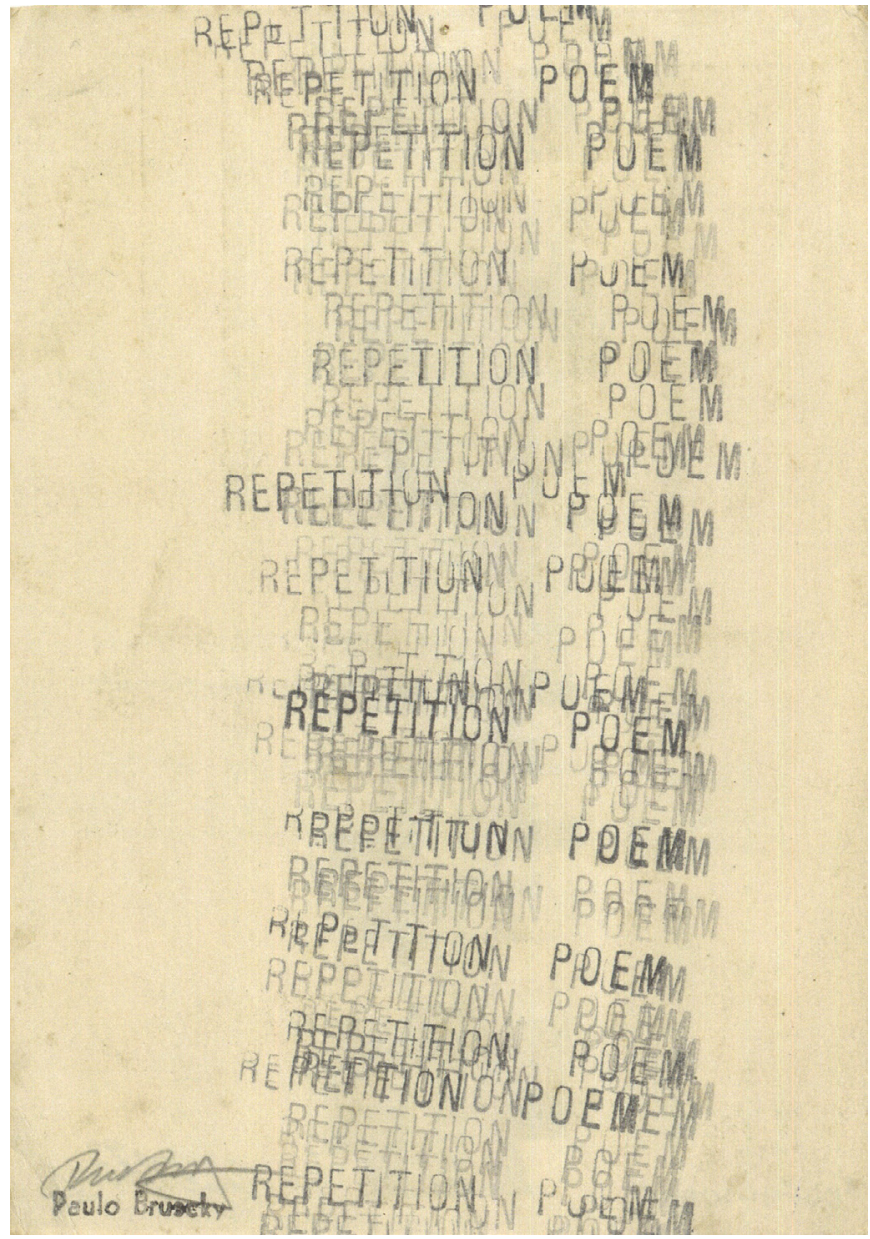

fig.1

Em uma página, o artista carimbou sobre uma folha de papel diversas vezes "Repetition Poem" e com as mais distintas intensidades do gesto de carimbar. Nesse caso, a repetição evoca dois sentidos: tanto é burocrática, fazendo referência aos carimbos de formulários, quanto faz referência aos tiros das situações de conflito entre militares e guerrilheiros no espaço urbano e rural. Resumindo: burocracia e violência. A referida obra de Paulo Bruscky contém algo de sua prática: ora é um chamado para a ação, ora é um espaço para a ação. Em outras obras com a técnica de uso de fotografias 3x4 - destinadas para documentos -, e colagem, o artista elabora totens agrupando fragmentos dos rostos por olhos recortados ("Ver com olhos livres") ou pelas bocas em Olfaladar, ambos de 1993 (Fig. 2). 


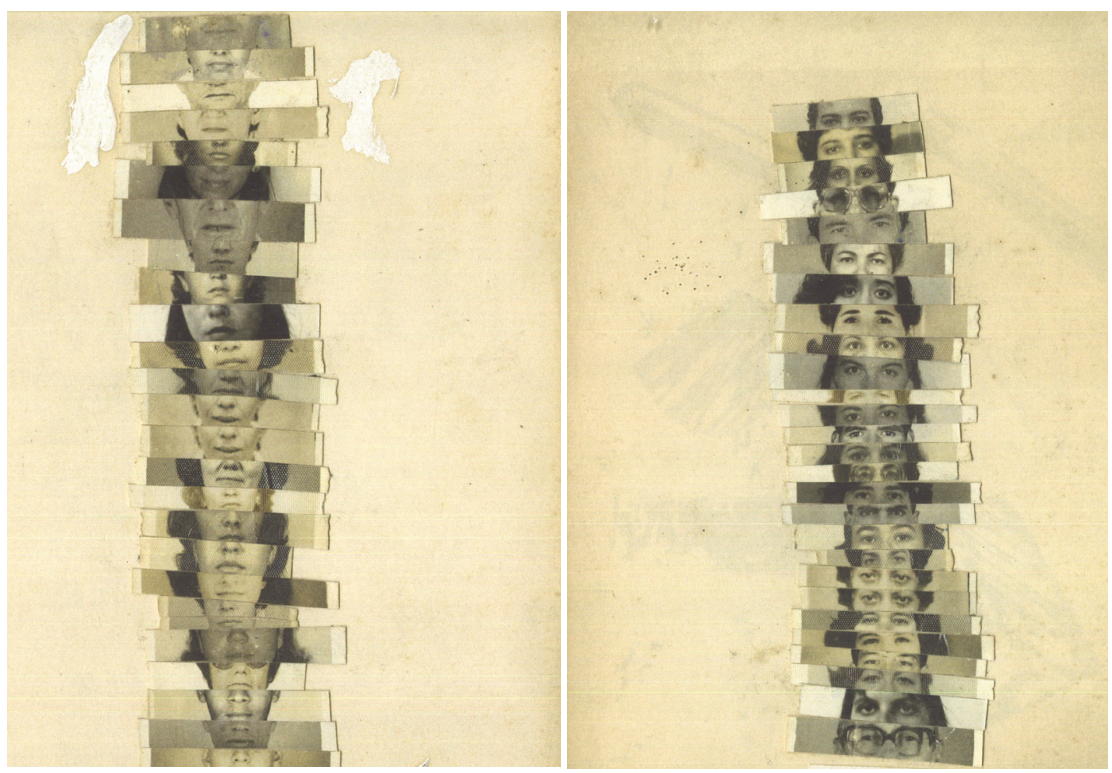

fig.2

Nestes dois totens há uma figuração de olhos que testemunham e no outro, organizado de modo semelhante, bocas e narizes formam uma coluna. Cortar as fotos que tem por finalidade a identificação e remontar os diferentes rostos, separando-os por olhos, de um lado, e bocas, por outro, implica em desfazer a ordem da identificação do rosto individual para documentos ou para cartazes que estampavam fotos de pessoas procuradas, sejam elas desaparecidos políticos ou guerrilheiros. Bruscky devolve um anonimato coletivo com os fragmentos desses rostos, de modo que testemunhas ambivalentes, as que podem ver ou falar, fazem parte de uma coletividade em tensão política e que agora estão, não nos arquivos do Estado, mas nos arquivos do artista. Ou a circular em museus e exposições, o que confere a este arquivo um outro valor de circulação para além de uma documentação fixa, estática.

Em Élégies documentaires, Muriel Pic encontrou nos documentos uma "experiência lírica" (2016: 81) que não responde com uma análise ao silêncio dos documentos em ambientes empoeirados, mas produziu versos tais como "tourner les pages de l'histoire n'est pas facile/ quand les peuples en soulèvent chaque ligne." ("virar as páginas da história não é fácil/ quando os povos se sublevam em cada linha”) (2016: 42). Há documentos que são contagiados pela época do poder político e militar e que passam a ser classificados como dossiês de inimigos do Estado. Aleixo e Nazareth haviam mostrado que o ritmo de leitura destes arquivos policiais do Estado pode alterar o tom monocórdico do poder que os detém. Em uma sociedade sob uma ditadura militar e mesmo sob uma frágil democracia na qual os agentes da ditadura não foram punidos, diferentemente de outros 
países latino-americanos, Argentina, Uruguai, Paraguai e Chile, a própria cidadania continua a ser fragilizada diariamente, sendo posta à prova pelos exercícios do poder diários da burocracia. Uma obra de 1976 de Ana Bella Geiger, destina uma atenção especial à língua: a artista desenhou quatro mulheres, dando foco à boca. Cada uma delas repete uma sílaba: "bu-ro-cra-cia". Acima "Diga conosco". A arte tornou-se uma espécie de espaço de alfabetização, inclusive para os artistas, onde uma única palavra, separada por hifens e por cores, marcam a separação fônica e silábica. Dado que escritores, intelectuais, artistas e por que não também determinados leitores e visitantes estavam sob suspeita, cabe a eles reaprender novas relações com a arte, inclusive a soletrar a violência codificada e disseminada na vida cotidiana.

Em termos de arquivo, a língua passa a ser um agente de codificação de atividades diretamente ou indiretamente engajadas. Os poetas e artistas como Ana Bella Geiger, Ricardo Aleixo, Paulo Nazareth e Paulo Bruscky sabem improvisar com um repertório vindo do campo de ação da língua que expõe e oculta a violência dos documentos. Ações que podem ser trágicas, épicas ou líricas, mas que também não deixam de ser paródicas, irônicas e dissimuladas. Há também uma ironia que se subleva do mundo dos arquivos. Paulo Bruscky se vale de tais recursos para expressar uma crítica à lógica do documento oficial. Ele elabora uma paródia do mundo burocrático e sua ação paródica se singulariza em que cada poema-documento que é comunicado em livros ou em ações públicas. Os recursos de Bruscky à linguagem arquivística neste caso fazem parte de uma ênfase na língua que marca uma realidade física do som e da estrutura gráfica das palavras. 0 arquivo, para ser comunicado, precisa encontrar uma forma para ser transmitido. Em outra obra de Bruscky, uma que faz parte da série Pelos Nossos Desaparecidos, de 1977, e que pertence ao acervo do Centro Georges Pompidou, o artista mostra a sua língua (Fig.3)

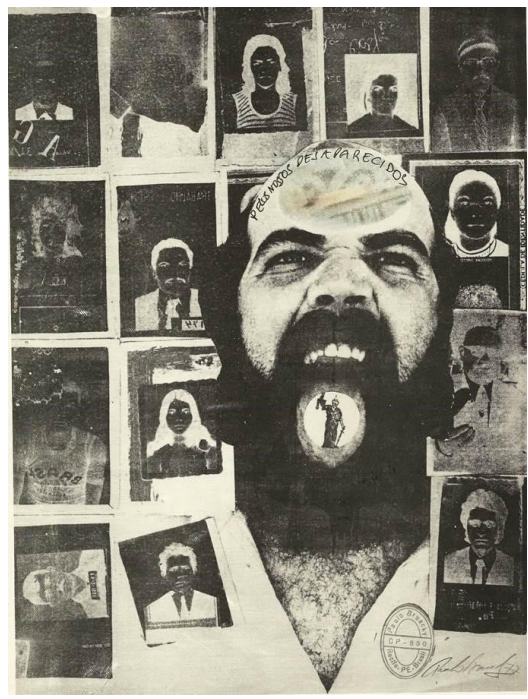

fig. 3 
Ele dá a língua que é uma expressão para designar um insulto. E na língua do artista há uma miniatura da imagem com Perseu com uma mão erguendo a cabeça da medusa e, na outra, porta uma espada. Ao redor do retrato do artista há outros retratos - em negativo - de pessoas desaparecidas na época da ditadura. Paulo Bruscky foi ator de uma guerrilha gráfica com ações concretas que foram possíveis a partir da ironia e da paródia nas quais podemos incluir o próprio gesto de arquivagem.

\section{Procura-se, Procuro-me: Paulo Bruscky e Lenora de Barros}

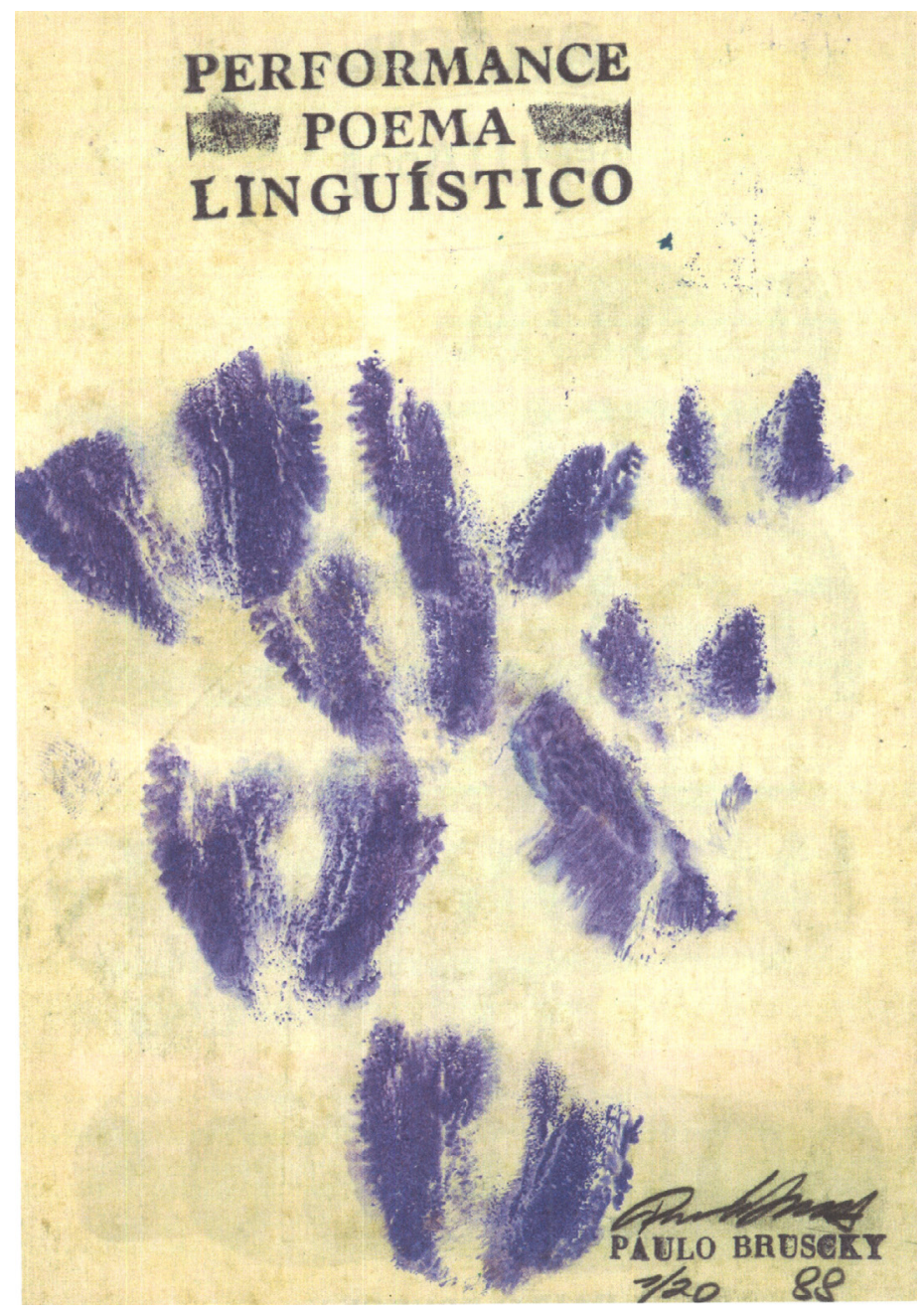

fig.4 
Em “Poema linguístico", de 1988, Bruscky utiliza a própria língua como carimbo (Fig. 4). Com a tinta azul tão marcada pelas insígnias administrativas e sobre uma superfície semelhante à um formulário, ele produz um conjunto de marcas que possuem afinidades com as antropometrias de Yves Klein. Os traços - da história da arte - deixados pelo músculo da língua sobre a página consideram a expressão da língua na sua simultânea mudez e ação. Valendo-se da linguagem dos cartazes e ainda no final dos anos setenta, Lenora de Barros realizou uma foto-performance "Poema" (1979) apresentou um outro confronto da língua com a letra, declinando a mudez e a ação da presença física da língua (Fig. 5).

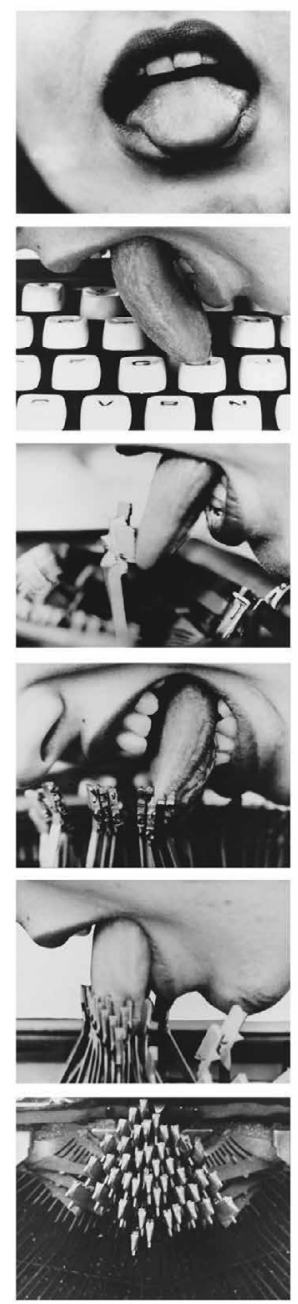

Fig.5 
"Poema" é uma sequência de seis fotos em que, de cima para baixo, a boca aberta mostra a língua, depois a língua lambe as teclas da máquina de datilografar até que, na terceira imagem, as extremidades de cada tecla onde estão os tipos entram em contato com a língua. As duas imagens seguintes mostram as letras contra a língua até que, na imagem final apenas as extremidades estão amontoadas. O que poderia haver de arquivístico na ação fotográfica da artista onde ela realiza um jogo de sedução e luta da língua contra a letra? Há uma distância mínima entre ambas que evoca prazer e tortura se lemos os gestos da artista à luz do repertório da época em que a sequência de imagens foi elaborada. Considerando que muitas informações foram obtidas pela polícia a partir dos mais diversos métodos de tortura, uma língua que age e protagoniza uma repetição incerta com a tinta dos carimbos, no caso de Bruscky, e um contato entre as extremidades da língua contra os tipos de metal de uma máquina de datilografar, como ocorre com a obra "Poema", 1979, de Lenora de Barros. Para Lenora de Barros, a língua é uma superfície: nela existe um duelo amoroso entre a palavra, na sua acepção linguística e saussuriana de parole e o aspecto processual, poético, numa dimensão mais clara quando associada a Roman Jakobson. Em uma entrevista feita com a artista, cuja formação é linguística, Lenora de Barros afirmou que "as funções da linguagem", de Roman Jakobson, foi uma de suas leituras mais significativas. Inclusive o conceito de "função poética" é adotado por ela como procedimento artístico. Em termos de procedimento, a dimensão física da língua ganha autonomia nas suas foto-performances, tornando a boca um espaço teatral para agenciamentos agramaticais na ação da língua na fotografia.

Na série "Procuro-me", de 2003, a artista investe contra o sentido despertado pelo estado policial ao buscar alguém foragido da justiça (Fig. 6).

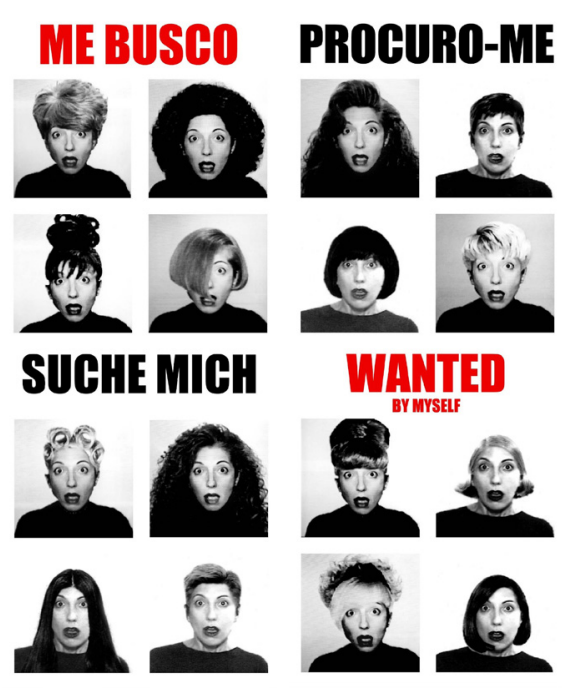

fig.6 
A série de autorretratos com perucas, geralmente quatro fotos por cartaz, cujas referências vêm das polaroides de Andy Warhol, introduzem à língua do arquivo um momento de chiste, de piada ou de ato falho que colapsam o arquivo da língua na homogeneidade do poder a partir de uma descarga contra a formalidade do poder institucional. Esse tipo de gesto faz parte de um vasto repertório de curto-circuito da própria língua que também tem traduções tais como "me busco", "suche mich", "wanted by myself".

Afirmar que a língua dispõe de um arquivo virtual de palavras e de expressões significa que a noção física de arquivo pode ser elevada a uma metáfora de gestos compartilhados dispensando o complexo e concreto sistema de conservação de documentos geralmente protegido por uma complexa rede de instituições, institutos, fundações e familiares. O lugar físico e intransponível do arquivo, aquilo que se refere ao seu princípio de consignação ao qual se refere Derrida: "le príncipe archontique de l'archive est aussi un principe de consignation, c'est-à-dire de rassemblement" "“o princípio arquôntico do arquivo também é um princípio de consignação, isto é, de reunião”) (1995: 14). Considerando a variante que agrupamentos de determinadas pessoas (estudantes, intelectuais, artistas, trabalhadores) podem ser considerado um ato suspeito, quais são as reuniões seguras para os arquivos. Quais arquivos estariam a salvo e com possibilidade de acesso e outros, suspeitos, ainda não estão acessíveis. No Brasil é uma expressão de uso comum para designar o assassinato e desaparecimento de testemunhas ou de pessoas que sabem muitas informações como "queima de arquivo".

"Queimar um arquivo", matar uma pessoa, é uma prática que não ficou restrita aos porões da ditadura no Brasil. Além disso, em meio a instabilidades políticas, práticas insurgentes e possibilidades de circulação em países como o Brasil onde nem sequer os arquivos não estão a salvo, correndo risco de incêndios, de roubo ou de danificação por falta de condições de conservação, a língua pode ser uma estrutura virtual que mantém vivo o arquivo, capaz de escondê-lo quando necessário ou de veicular variações de uma narrativa. Nesse sentido, essas práticas lidam com estas duas instâncias de modo relativamente assimétrico e desigual. Com uma estabilidade limitada mantêm um arquivo pessoal, mas também elas são agentes da circulação de seus próprios arquivos. Os artistas se tornam arquivistas que lidam com os dois momentos: eles agrupam, catalogam, consignam, mas também ressaltam as instabilidades políticas de conservação, mesmo de museus, do que corre o risco de desaparecer, como foi o caso do acervo do Museu Nacional no Rio de Janeiro e o grande incêndio que consumiu quase todo o acervo e arquivo no dia 2 de setembro de 2018 e de outros incêndios que já fizeram desaparecer uma tela de Picasso no Museu de Arte Moderna do Rio de Janeiro ou parte do acervo do artista Hélio Oiticica.

\section{Um arquivo-outro da língua: poesia e procedimento.}

A experiência da língua e arquivo é múltipla e varia de acordo com cada obra e abordagem artística e arquivística. As palavras sobre superfícies diversas - sejam elas página, parede ou fotografia -, revelam camadas de um processo de arquivagem contínuo: o 
espaço gráfico se prolonga com o fenômeno da voz, a oralidade e a escrita se entrelaçam numa dinâmica da língua que partilha de uma instância política. Há um nexo inseparável entre forma e conteúdo, entre vida e arquivo. Por esse viés, a figura do artista-arquivista desempenha uma característica particular na medida em que eles chamam a atenção para procedimentos de trabalho que vão além da função metalinguística de um trabalho que conta o processo, pois, afinal, a obra entra em acordo com o procedimento, como pode ser observado a partir da seguinte consideração de Roman Jakobson: "Si les études littéraires veulent devenir science, elles doivent reconnaître le procédé comme leur "personnage unique" ("Se os estudos literários querem se tornar ciência, eles devem reconhecer o procedimento como "personagem único") (1977: 17). A afirmação de Jakobson foi levada a sério por Haroldo de Campos que, ao longo de sua obra, passou a investigar o caráter da metalinguagem sobretudo na sua atividade crítica. Além disso, o caráter de procedimento é fundamental para os artistas em questão, Paulo Bruscky, Lenora de Barros e Ricardo Aleixo. Todos, em alguma medida, mantêm um arquivo ativo e presente nas suas respectivas obras e ações.

A língua do arquivo possui seus personagens únicos que ultrapassam o caráter individual e sua função na sociedade, seja ela nobre ou inconfessável, pois através de uma nova circulação, ela permite o estabelecimento de um espaço exterior no qual, eles, os personagens estavam fechados. Esse espaço exterior, em literatura, pode ser chamado a partir de Jakobson de um conjunto de procedimentos que necessitam de outros agentes, que neste caso são poetas e artistas. Nesse sentido, a prática arquivística de Paulo Bruscky produziu um capítulo incontornável da história da poesia visual brasileira. De 30 de maio a 8 de setembro de 2019, no Sesc São Paulo, Bruscky expôs o resultado de mais de cinquenta anos de prática de arquivo. "É na História - e a partir dela - que nos movemos" (2019b: 9), escreveu o artista. Ao mover-se na e a partir da história, Paulo Bruscky elabora uma rede complexa de tempos que se orienta no barroco do século XVII, com Gregório de Matos, na figura outsider do romantismo Sousândrade, no século XIX e nas práticas experimentais ao longo do século XX, que compreende a obra de Oswald de Andrade, de Vicente do Rêgo Monteiro, da poesia concreta, do poema-processo com Wlademir Dias-Pino, dos poemas-objeto de Lenora de Barros. 0 arquivo de Paulo Bruscky abre um chamado para a ação: a leitura do tempo presente de uma comunidade de poetas e de artistas que se valem, por sua vez, da virtualidade arquivística da língua. O arquivo, para Paulo Bruscky, nunca é abstrato ou objeto de fetiche, mas um modo de manter as formas documentais em troca aberta com o presente.

Diferentemente de Bruscky, Aleixo mantém a troca com o presente desde seus arquivos pessoais. Uma pessoalidade que tem seu destino público. Aleixo rearticula sua ancestralidade afro-brasileira pela dimensão familiar do arquivo, pois ele incorpora em seus livros e em poemas fotografias retiradas de álbuns, cuja literalidade pode ser reconhecida no poema "Álbum de família": "Meu pai viu Casablanca três vezes (duas/ no cinema e uma na TV). Meu avô/ trabalhou na boca da mina. Meu bisavô/ foi, no mínimo, 
escravo de confiança" (2018: 46). É aqui que o álbum de família perde sua função de memória íntima de um arquivo familiar para se tornar um procedimento do arquivo da língua contra a língua do arquivo, cuja fricção pode ser lida no poema "Língua":

\author{
era o meu \\ aquele \\ corpo transido \\ pela espera \\ vinte e nova \\ noites já e \\ apenas \\ o rumor de \\ uma para \\ mim incompreensível \\ mas \\ esplêndida língua \\ se formando \\ ainda \\ pode ser que se \\ decompondo \\ (2018: 52)
}

A recusa de atribuição de sentido a uma frase, sua hesitação que é uma resistência da poesia, no sentido proposto por Jean-Luc Nancy (1997), no qual o poema estabelece outra unidade de sentido a partir da inseparabilidade de formação e decomposição. Por essa "língua" o arquivo se move em termos de "moeda concreta da fala", para recuperar a expressão de Sapir via Augusto de Campos. Em outro poema "Sobre escrever", lê-se que "não escrever porque este,/ antes e acima de tudo,/ é o melhor turno/ para não escrever" (2018: 81). Uma escrita que se escreve apesar de tudo porta também os traços da voz, uma insistência de timbres daqueles que não organizaram discursos, que vivem o risco da violência e de ingressarem ao mundo do arquivo em uma descida aos infernos, onde lá permanecerão alinhados pelas palavras-chave violência, pobreza, tortura, assassinato, prisões políticas. Por outro lado, Ricardo Aleixo - próximo de Bruscky - dispõe de um 
arquivo de vinte mil objetos, desde quando ele organizou a primeira Bienal Internacional de Poesia de Belo Horizonte, em 2001. Essa prática de alguns artistas no Brasil marca um desejo concreto da arte que passa pelas invenções da língua, incluindo a sua ação silenciosa e performática.

$\mathrm{O}$ arquivo da língua e a língua do arquivo fazem parte de uma dinâmica que pode muito bem se acoplar a práticas de deslocamento de sentido, esvaziamentos institucionais e descentramento de poderes: o "procura-se" impessoal e institucional dos cartazes de Lenora de Barros, por exemplo, pode ser destacado de sua linguagem policialesca para ser uma prática contínua de investigação poética. Substitui-lo o esvaziamento de denúncias anônimas de pessoas procuradas por uma política da vagabundagem, como propõe Georges Didi-Huberman, em Idas y vueltas, pode muito bem se aliar a demandas filológicas dos arquivos no século XXI. Graciela Goldchlunk e Juan Antonio Ennis, na apresentação de Las lenguas del archivo. Filologías para el siglo XXI, escreveram que as práticas filológicas que falam as línguas do arquivo já não buscam a "recuperação de uma totalidade pré-existente, mas transitar pelo arquivo a partir de uma fragmentação que é a regra e cujo princípio construtivo sempre volta à montagem" (2021c: 9). É esse valor heurístico que a língua do arquivo investe, numa reunião arquôntica que provoca novas vizinhanças por diferenças em procuras que não dissociam o momento literal da palavra da contingência política. $O$ arquivo, em toda a sua virtualidade, não deixa de circular no mundo, ainda que seja por tudo aquilo que, na impessoalidade de um "procuro-me" ajuda a reconfigurar os sentidos do "procura-se" que agora não passa totalmente desapercebido em suas funções poéticas, ainda que tenha traços imperceptíveis, inapagáveis e incapturáveis do arquivo.

\section{NOTAS}

\footnotetext{
* Eduardo Jorge de Oliveira é professor assistente de Estudos Brasileiros (Literatura, Cultura, Media) no Instituto de Romanística da Universidade de Zurique - UZH. É membro do Centro da América Latina (LZZ) e do Centro de Artes e de Teoria da Cultura, da mesma universidade. É autor de A invenção de uma pele: Nuno Ramos em obras (Iluminuras, 2018). Signo, sigilo: Mira Schendel e a vivência da escrita imediata (Lumme Editor, 2019). Suas pesquisas e centros de interesse são: literatura e artes visuais, estudos da animalidade e limites da teoria literária com a estudos etnográficos.
} 
${ }^{1}$ A peça sonora pode ser ouvida em: https://www.youtube.com/watch?v=aVuilb72EJI (último acesso em 11.10.2021)

2 É lapidar o comentário de Jean-Christophe Bailly a propósito de Benveniste e que tece afinidades elementares entre o traço da letra e a dimensão fônica da voz até atingir o que ele chama de "intimidade", uma construção essencial para a literatura e que encontra no arquivo o espaço por excelência para uma articulação entre voz e escrita. Menos que uma polaridade entre palavra e imagem, os documentos, os arquivos e as imagens em si chamam a atenção para tudo aquilo que pode ser "falado". Por sua vez, a escrita coincide com um espaço de escuta de intimidades desdobradas na própria dimensão política, histórica e literária:

Car ce à quoi nous amène au fond ce long détour par la figure - les pelotes enchevêtrées, les lignes errantes, la carte ou le cercle - c'est précisément à la fonction première de l'écriture, à ce qui fait qu'elle est d'abord, écoutons Benveniste, une image de la langue: "La graphè "représente" la phonè, tel est le principe", écrit-il dans ses Dernières leçons, consacrées justement en grande partie à l'écriture, qu'il définit comme le moyen par lequel le langage se rend intégralement conscient de lui-même. Mais s'il accorde bien que par l'écriture "la langue est soudain convertie en une image de la langue" et s'il emploie effectivement le terme d'image, ce n'est pas sans précautions (et donc avec des guillemets) qu'il dit que la graphie représente la phonie. Cette petite hésitation reflète bien la singularité figurante de l'écriture : image qui ne représente pas vraiment, ou représentation qui n'est pas véritablement une image, comme on voudra, l'écriture avance non comme le simple mime de la parole, mais comme un système d'équivalences devenu quasi autonome. Or, c'est cette autonomie qui l'a libérée comme puissance instinctive de notation, l'écriture étant (Benveniste encore) non seulement une transcription de la parole, un passage du sonore au visuel, mais aussi "une transposition du langage intérieur", ce qui revient à dire qu'à travers elle le chemin qui est offert à la pensée est celui de sa propre identification. Ce langage intérieur quasi permanent, qui se continue même la nuit, via les discours qui se tiennent dans le rêves, et dont Benveniste dit qu'il est allusif, rapide, incohérent, et qui est tel parce que justement il n'est pas destiné à devenir parole et à se tourner vers l'extérieur, l'écriture en est l'écoute et l'approfondissement, la mise au jour discontinue. On le devine aussitôt, ce qui 'ouvre ainsi dans le droit fil de ce langage dont chacun d'entre nous pourrait dire, comme Augustin l'a dit de Dieu, qu'il est en lui “intimior intimo meo", plus intime à lui que lui-même, c'est au sens le plus générique, le plus dispendieux et le plus vif, la voie même de la littérature, dont on pourrait dire alors qu'elle est la forme déployée de cette intimité" (Bailly 2016: XIV) .

${ }^{3}$ Exposição ocorreu de 22 de agosto a 24 de novembro de 2019 e seu objetivo principal foi sensibilizar as pessoas para a importância da prese 


\section{BIBLIOGRAFIA}

Aleixo, Ricardo (2018), Pesado demais para a ventania. Antologia poética. São Paulo, Todavia.

Alferi, Pierre (2007), Chercher une phrase. Paris, Christian Bourgois,.

Bailly, Jean-Christophe (2016), L'ineffacé. Brouillons, Fragments, Éclats. « Le lieu de l'archive». Normandie, Éditions de l'IMEC.

Benjamin, Walter (2000), "Sur le langage en général et sur le langage humain". Fuvres I. Paris, Folio-Gallimard.

Bessa, Sergio (2015), Paulo Bruscky: Poesia Viva. São Paulo, Cosac Naify.

-- (2014), Paulo Bruscky: Art is our last hope. New York, Bronx Museum, Phoenix Museum.

Bonas, Marília; Volz, Jochen (2019a), "Meta-Arquivo e Memorial da Resistência de São Paulo:

novas janelas para a investigação do período da ditadura civil militar brasileira". Metaarquivo. São Paulo, Sesc.

Brusky, Iuri; Brusky, Paulo (2019b), História da poesia visual brasileira. São Paulo, Sesc.

Campos, Augusto de; Campos, Haroldo de; Pignatari, Décio (org.) (2006), Teoria da Poesia

Concreta. Textos críticos e manifestos 1950 - 1960. São Paulo, Ateliê.

Derrida, Jacques (1995), Mal d'archive. Une impression freudienne. Paris, Galilée.

Didi-Huberman, Georges (2021b), "Idas y Vueltas ou la politique du vagabondage". Les Cahiers du Musée national d'art moderne. Hiver 2020/2021, n. 154. Paris, Centre Georges Pompidou: 3-49.

Ennis, Juan; Goldchluk, Graciela (2021c), Las lenguas del archivo. Filologías para el siglo XXI. La Plata, Facultad de Humanidades y Ciencias de la Educación, Universidad Nacional de La Plata.

Farge, Arlette (2017), O sabor do arquivo. Trad. Fátima Murad. São Paulo, Edusp [1989].

Heller-Roazen, Daniel (2017), Langues obscures. L'art des voleurs et des poètes. Trad. Françoise e Paul Chamla. Paris, Seuil.

Jakobson, Roman (1977), "Fragments de la nouvelle poésie russe". Huit Questions de Poétique. Paris, Seuil.

-- (2003), Essais de Linguistique Générale. 1. Les fondations du langage. Trad. Nicolas Ruwet.

Paris, Les Editions de Minuit, 2003 [1963].

-- (1973), Questions de Poétique. Paris, Seuil.

Marighella, Carlos (2019c), Chamamento ao Povo Brasileiro e outros escritos. Vladmir Safatle (Dir.). Col. Explosante. São Paulo, Ubu.

Nancy, Jean-Luc (1997), Résistance de la poésie. Bordeux, William Blake \& Co.

Perloff, Marjorie (2021a), Infrathin. An Experiment in Micropoetics. Chicago. Chicago University Press.

Pic, Muriel (2016), Elégies documentaires. Paris, Macula. 